\title{
Correction to: Numerous Russell bodies in multiple myeloma
}

\author{
Juan Zhang ${ }^{1}\left(\mathbb{D} \cdot\right.$ Yuan $\mathrm{He}^{1} \cdot$ Mingyong $\mathrm{Li}^{1}{ }^{1}$
}

Published online: 2 May 2019

(c) Japanese Society of Hematology 2019

\section{Correction to:}

International Journal of Hematology (2019) 109:627-628 https://doi.org/10.1007/s12185-019-02634-w

Publisher's Note Springer Nature remains neutral with regard to jurisdictional claims in published maps and institutional affiliations.

Owing to an unfortunate mistake at the typesetter's end, Fig. 1 was published incorrectly which is corrected in this correction (Fig. 1). The authors are not responsible for this procedural lapse.

Fig. 1 Numerous Russell bodies in multiple myeloma
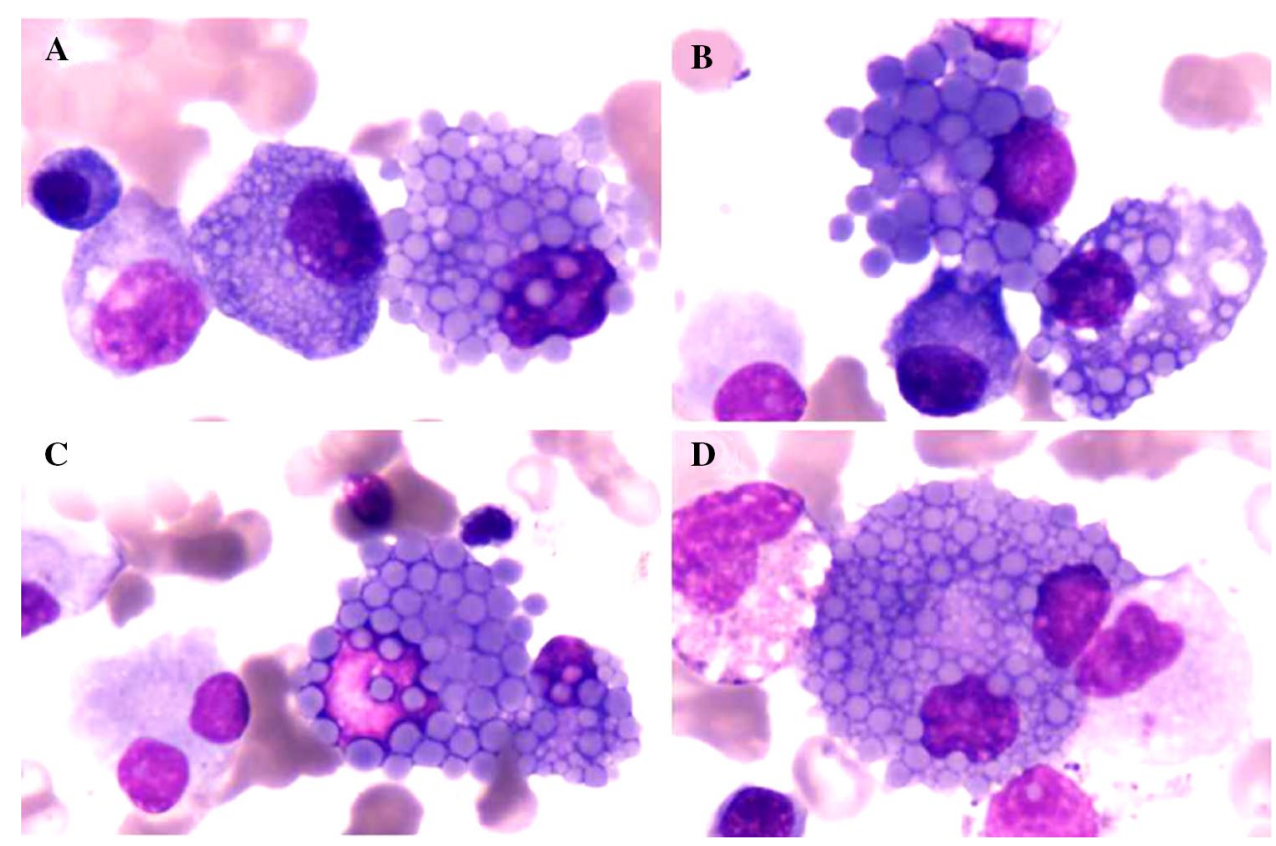

The original article can be found online at https://doi.org/10.1007/ s12185-019-02634-w.

Mingyong Li

limingyong0115@163.com

1 Clinical Laboratory of Sichuan Academy of Medical

Science and Sichuan Provincial People's Hospital,

School of Medicine, University of Electronic Science and Technology of China, No. 32 West Second Section First Ring Road, Chengdu 610072, Sichuan, China 